\title{
Effects Of The Law On The Marketing Of Infant Foods In Ghana
}

\author{
Goski Alabi, Institute of Professional Studies, Legon - Accra, Ghana \\ Joshua Alabi, (E-mail: ipsdp05@yahoo.com), Institute of Professional Studies, Legon - Accra, Ghana \\ Isabella Sagoe Moses, National Child Health Coordinator, Ministry of Health, Ghana
}

\begin{abstract}
Six years into the implementation of the Ghana Breastfeeding Promotion Regulations 2000 (LI 1667), this paper takes a look at how the implementation of the regulations has affected both the promotion of commercial infant foods and mothers feeding options in Ghana. The study reveals that the regulations have restricted promotion of designated products to health care facilities basically to the provision of technical informational materials to health workers and promotion through labeling of products. Direct advertisement of designated products to the general public was virtually non existent through out the study, though there was a general lack of awareness of the existence of the regulations on the part of the general public. The study further suggests that mothers feeding options have been influenced by both the existence of the regulation and the strong breast feeding advocacy together with the Baby Friendly Hospital Initiative. Most mothers choose to breastfeed either exclusively or sometimes with water for the first three months of their babies life. The paper further reveals that mothers generally supplemented with other foods not only infant formula from the fourth month onwards because of employment and other social and economic reasons. These practices are quite different from the years before the Regulations. Enhanced enforcement of the Regulation, awareness creation and further research into impact of the regulations and other infant feeding practices could result in significant gains in compliance and appropriate infant feeding practices.
\end{abstract}

\section{BACKGROUND TO THE EXERCISE}

ood infant feeding practices are the foundation of a healthy life. Infant feeding practices have been shown to affect infant and young child survival and the long-term health of every adult. Improving breastfeeding practices has been reported to top the list of life-saving actions and low-cost preventable interventions for children, especially in poor communities (Lancet 2005).

It is estimated that each year, more than ten million children die before the age of five, mostly from preventable causes and almost all of these deaths occur in poor countries. Further to this, about forty-one percent (41\%) of these deaths occur in sub-Saharan Africa alone (Black et al 2003). Most of these deaths have also been reported to occur in the infantile stages with the majority occurring in the neonatal stages. Among the key issues worth considering in mitigating the problem of child death is the importance of under nutrition. Under nutrition has been identified as an underlying cause of child deaths associated with infectious diseases. According to the report by Black et al in the Lancet series 2005, "Infants aged 0-5 months who are not breastfed have a seven fold increased risk of death from diarrhoea and pneumonia compared with infants who are exclusively breastfed" (Lancet 2005, Victora et al 1989). "At the same age, non exclusive rather than exclusive breastfeeding results in a two fold increased risk of dying from Diarrhoea and pneumonia" (Lancet 2005, Arifeen et al 2001). The World Health Organization (WHO) has again confirmed that an estimated 1.5 million infants who die each year could have been saved if they had been breast-fed (WHO-AFRO 2005). In Africa, breastfeeding is crucial because it is considered the most low cost life saving intervention with the potential to reduce $13 \%$ of annual death among children under five (Lancet 2005). Breast milk has therefore often been described as nature's gold for infants. For babies everywhere, the benefits of breastfeeding are undisputed but, for infants in developing countries, breastfeeding is imperative. 
The 2006 World Bank report "Repositioning Nutrition as Central to Development" contends that malnutrition and its irreversible consequences such as reduced intelligence, stunted growth, poor academic performance, lowered educational levels, inability to perform job functions, among others are the most damaging causative factors in the perpetuation of poverty. "Reduce malnutrition, says the World Bank report, and poverty is reduced as well". Central to the report's recommendations is the firm statement that steps to prevent malnutrition must occur during the first 2 years of life. Breastfeeding is recognized as the single most important long-term preventive measure that can be taken to combat malnutrition. The report also identified the International Code of Marketing of Breastmilk Substitutes (the Code) as an important policy intervention.

"Data from the most recent five-year period suggests that one in every nine Ghanaian children dies before reaching age five. "Nearly three in every five of these deaths occur in the first year and neonatal deaths account for two thirds of deaths in infants" (GDHS 2003). In addition to the high mortality, infant morbidity also has its own social and economic implications. A recent study in Ghana indicated that promotion of early initiation of breastfeeding has the potential to make a major contribution to the achievement of the child survival Millennium Development Goal (MDG 4) $)^{1}$. The World Bank Report noted that "Malnutrition remains the single biggest contributor to child malnutrition." The report further added that unless policies and priorities are changed, the scale of the problem of malnutrition will prevent many countries from achieving the MDGs especially in sub-saharan Africa" (Bardouy and Sarbid 2006). According to this study, 16\% of neonatal deaths could be saved if all infants were breastfed from day 1 and 22\% if breastfeeding started within the first hour (Edmond et al 2006, Bahl et al 2005).

The very survival of infants particularly neonates, depends on the immune-boosting properties of mothers' milk. Available evidence has shown that infant formula is not just inferior but infact a hazard because it is not a sterile product as normally presumed. In some cases infant formula has been the cause of disease and even death in infants in both developing and developed countries (WHO Food Safety Department Alert 2005, INFOSAN 2005, WHA 2004).

The numerous advantages of breastfeeding, the risks of bottle feeding and the excessive and inappropriate use of artificial infant feeding products made it imperative for the WHO and UNICEF to intervene (Mahler 2005). This led both the WHO and UNICEF to move for the adoption of the International Code of Marketing of Breastmilk Substitutes in 1981 and subsequently other WHA resolutions in respect of infant and young child nutrition including the Global Strategy for Infant and Young Child Nutrition (2002), (Sokol 2005, WHA 2001, WHA2002). All these initiatives have been taken to protect the health and nutrition of infants and to reduce infant mortality.

\section{Factors Affecting Breastfeeding Rates}

In spite of the benefits of breast-feeding, and all the interventions and provisions initiated to promote, support and protect breastfeeding, the rate of breast feeding in many countries is still generally low. This has partly been attributed to socio-economic and demographic trends, lactation problems as well as the fact that breast feeding is still not as protected as it should be twenty-five years after the adoption of the International Code (IBFAN 2006, RNCOS 2006, and Walker 2003). In sub Saharan Africa only 27\% of infants under six months are reported to be exclusively breast-fed (Walker and Adams 2000). The Baby Food market has been reported to be growing consistently, however it is said to have witnessed a phenomenal growth since the year 2003. This growth has led to the transformation of the baby food industry across the globe. The RNCOS Research report observed that new markets for the baby foods are emerging fast and are stretching beyond the traditional strongholds like North America and Europe.

Studies have shown that the complexity of factors that affect breastfeeding include the aggressive marketing of breast milk substitutes, practices at health facility levels that have the potential to undermine breastfeeding, cultural feeding practices, economics of feeding, convenience, socio economic and demographic factors, availability as well as employment concerns (Sokol 2003, Walker and Adam, 2003, RNCOS 2006).

However, two key factors that have been identified to contribute largely to the decline in breastfeeding and the entrenchment of bottle feeding are commercial promotion of infant food products and health care practices that

\footnotetext{
${ }^{1}$ MDG 4 urges countries to reduce infant mortality by two thirds by the year 2015 using 1995 rates as a reference
} 
encourage the use of these products (Sokol 2003). Most mothers on the other hand are reported to cite insufficiency of breast milk and employment concerns as the common reasons regarding their inability to breastfeed (Walker and Adam, 2000). On the contrary, marketing experts have confirmed that "the performance of the baby food industry is sensitive to the perception of the consumers". The report further cited consumer purchasing power and changing socio-economic and demographic factors as factors as factors driving the baby food industry (RNCOS 2006). Consumer perception is formed at two levels before and after consumption. Before consumption, consumer perception is formed through marketing activities and after consumption by the experience utility relative expectations the product which is important for repetitive purchasing (Steenkamp and Van Trijp 1998). This quality guidance model proposed by Steenkamp and Van Trijp and the RNCOS report confirms the two key factors that have been identified to contribute to the entrenchment of bottle feeding. The RNCOS Report also indicated that the uniformity of the emerging socio-economic patterns in the world is driving the growth of baby food market across geographical regions. This means that any strategic intervention aimed at reducing infant mortality and improving infant health and nutrition must aim at improving breastfeeding. Infant health improvement interventions should therefore focus primarily on understanding the drivers that move the baby food market and influence mothers feeding options. Such interventions should aim at promoting breastfeeding whilst regulating the promotion of commercial infant food products and practices of health professionals that discourage breastfeeding among others. The later is exactly what the Code and the LI 1667 seek to do. A leading baby food manufacturer has confirmed the need for regulation and further indicated that "the major area of improvement in the application of the WHO Code has to do with enforcement, which implies monitoring by governments or under the auspices of governments (Nestle 2003). However, the Code calls upon manufacturers and distributors to regard themselves as responsible for ensuring that their conduct at every level conforms to the Code. While it cannot be disputed that governments have a vital role to play in ensuring the success of any legal instrument, monitoring is an activity that can legitimately be taken up by anyone having an interest in Code activities. Here, the Code lays down in Article 11 the role of manufacturers and distributors themselves to be responsible for ensuring that their conduct at every level conforms to the Code. This can be done by self-monitoring. Whilst self-monitoring is important as an internal check against abuse, it offers no assurance regarding the monitoring standards or that there will be no cover-up of excesses. This is where independent monitoring by NGOs plays a vital role. Founded on Article 11.4 of the Code, NGO monitoring counterbalances the self monitoring that manufacturers and distributors claim to do and in many cases, fill the gap left by governments that do not see Code monitoring as a priority. Halfdan Mahler WHO Director General from 1973-1988 in Allain's Development Dialogue 2005, fighting an old Battle in a New World' noted "It is true that without the NGOs, ......there would never have been a Code. The role of NGOs and Civil Society continues to be more relevant than ever in protecting the health of the voiceless and most vulnerable. As indicated by Annelies Allian, "Three Systems: government, business and people influence each other at all levels" (Allian 2005).

\section{The Case Of The Breast And Bottle In Ghana}

In Ghana, despite the high breastfeeding prevalence of $97 \%$, the majority of children are not fed in compliance with the WHO/UNICEF recommendations (WHA 2001, GS-IYCF, WHA 2002, GDHS 2003). These recommendations call for a period of six months exclusive breastfeeding and the introduction of complementary foods after the six months with continuous breastfeeding for at least two years. Recent Ghanaian data indicated that fifty three percent $(53 \%)$ of children are breastfed exclusively for six months; however exclusive breastfeeding drops sharply from 65\% in 2 to 3 months to 39\% at age 4-5 months. Six percent (6\%) of infants aged 2-3 months and 32\% at age 4-5 months are receiving supplementary foods in additions to breast milk (GDHS 2003). This means that many infants could be exposed to bacterial contamination and poor quality foods even if they started off well with early initiation of exclusive breastfeeding. The duration of paid maternity leave in Ghana is twelve weeks and this is believed to account for the sharp decline in breastfeeding rates from the fourth month onwards. However, twelve percent $(12 \%)$ of infants less than six months are reported to be bottle fed and this reaches a peak of $15 \%$ at age $4-5$ months (GDHS 2003). There are indications that improvements in infant mortality rates recorded during the 1990s are being eroded (Ghana Human Development Report 2004). Data from the GDHS further reveals that there has been a "slowing down in decline of the infant mortality rate in Ghana over the past five years. Whereas infant mortality was 77 per every 1000 live births in 1988, it came down to 66 in 1993, then to 57 in 1998 and went up to 64 in 2003". The report also indicates that there was little difference between breastfeeding rates of 1998 and 2003. Whereas breastfeeding rates within one hour after birth and 24 hours after birth went up, rates begin to decline after the third 
month. The GHDR pointed out that child malnutrition is one of the two key factors among others accountable for the increase in child mortality rate over the last five years, that is between 1998 - 2003 (GHDR 2004). This is during a period when the Ghana Breastfeeding Promotion Regulation, 2000 (LI 1667) among other interventions is supposed to be in force. What is eroding the gains that have been made over the years at a time when interventions have been introduced to achieve more?

The question is:

- How has the Breastfeeding Promotion Regulation affected promotional practices and mothers feeding options in Ghana?

The study therefore sought to find answers to this question.

\section{AIMS AND OBJECTIVES}

The objective of the exercise was to monitor the level of compliance to the "Breast feeding Promotion Regulations, 2000 (LI 1667). The main aim was to ascertain how compliance to the regulation affects promotional practices of baby food companies and how this influences the feeding options of nursing mothers

\section{METHODOLOGY}

The assessment was carried out from...November 2004....to ...June 2005. It had three main components. These included Reviews, Contacts and Field Activities. These included Reviews of relevant documents, Focus Group Discussions, Questionnaires (The Modified SIM Tool), interviewing of health workers, Traditional Birth Attendants (TBAs), post-natal mothers on the ward, mothers at ante-natal and child welfare clinics and mother support groups in various communities. Interviews were held with grocery, gift shop and pharmacy shop owners / attendants. Observations were also carried out at all the places visited. There were media review of national and local FM stations and news papers.

One of the three standard Code Monitoring tools ${ }^{2}$, the Standard IBFAN Monitoring Tool (SIM Tool) was modified and adapted for the exercise. Where possible, the exercise was carried out in two (2) urban and two (2) rural communities in each selected Region on random basis. The exercise was carried out by assessing practices at various health facilities, inspecting groceries, gift shops, pharmacies and the media (TV, Radio and Print media). The sample units for every selected site whether rural or urban was made of:

- $\quad$ Ten Health Facilities ( five (5) big and five (5) small (comprising Two (2) small government and three (3) private health facilities including clinics, maternity homes and TBAs). ${ }^{3}$

- $\quad$ Ten (10) groceries/pharmacy/gift shops.

- $\quad$ Ten (10) nursing mothers

- $\quad 10$ Health workers and Traditional Birth Assistants (TBAs) where possible.

Data were entered, tabulated, and analyzed with SPSS. Information gathered from focused group discussions were transcribed and used for analysis

\footnotetext{
2 "Currently three international models of monitoring exist: the WHO Common Review and Evaluation Framework (WHO/NUT/96.2), the International Baby Food Action Network (IBFAN) Monitoring Forms Manual, and the Interagency Group on Breastfeeding Monitoring (IGBM) protocol currently in draft. The third has the advantage of assessing compliance with both the international code and national legislation and describes clearly the sampling method used". (Waterston and Tumwine, BMJ 2003 326: 113-114)

${ }^{3}$ For purposes of this study a TBAs, Maternity homes, health post, health centers and clinic with less than five beds were considered as small facilities.
} 


\section{Sampling}

Six regions in Ghana were purposively sampled. These included the three administrative Northern Regions (namely: Northern region, Upper East Region and Upper West Region) and three administrative Regions in the south (namely; Greater Accra, Western Region and Central Region). The three Northern Regions were selected because it has been officially reported that malnutrition among children is most prevalent in these regions (GDHS 2003, GHS 2004). The Western Region was selected because of its location as a border community to ascertain the effects of Border activities on compliance if any and the Greater Accra and Central Regions because of their urbanized and rural nature respectively.

For the purposes of this study "infant" means a child from birth up to the age of twelve months and "designated product" includes infant formula, any other product marketed or otherwise represented as suitable for feeding infants up to six months of age, follow-up formula, feeding bottles, teats and pacifiers and a product so designated by the Minister as provided for by the Ghana Breastfeeding Regulations, 2000 (LI 1667).

\section{Quality Assurance Measures}

- $\quad$ Only trained code monitors were used for the exercise. All those selected for the Code monitors training were senior health inspectors, regional regulatory officers of the food and Drugs Board (FDB) or regional nutrition officers who had some operational experience in the field.

- $\quad$ Team members were selected from the various regions with leaders from the National Monitoring Coordination Committee. The monitoring tools used had been pre-tested and standardized in previous national monitoring exercises conducted by the International Baby Food Action Network (IBFAN) in conjunction with the Ghana Infant Nutrition Action Network (GINAN).

- At the end of each day the teams met to review the data collection process and to plan for the next day.

\section{THE AIMS AND SCOPE OF THE INTERNATIONAL CODE OF MARKETING OF BREAST MILK SUBSTITUTES}

The Code is a global recommendation adopted by the WHA in 1981 (WHA 34.22 (1981) through a vote with 118 votes in favour, 1 against and 3 abstentions (Sokol 2005). It states that breastfeeding must be actively protected and promoted in all countries; and stresses that adoption and adherence to the Code is a minimum requirement; and finally urges all Member States to translate the Code into national law and/or regulations.

The Code aims at protecting and supporting breastfeeding by ensuring appropriate marketing and distribution of breastmilk substitutes. It applies to breastmilk substitutes, when marketed or otherwise represented as a partial or total replacement for breastmilk. Breastmilk substitutes can include food and beverages such as infant formulae and any milk and cereal product, vegetable mixes, juices and baby teas marketed as suitable for babies less than six months of age. It also covers products marketed as a replacement for breastmilk and therefore includes follow-up milks or milks recommended for babies from six months to two years of age since the WHO recommendation for breast feeding is up to at least two years.

The Code bans all advertising or other forms of promotion of products under its scope. It does not allow point of sale promotion. Other provisions include:

- $\quad$ No free samples to mothers, health care workers or their families.

- $\quad$ No promotion of products which include product displays, posters or distribution of promotional materials. No use of mother craft nurses or similar company-paid personnel.

- $\quad$ No gifts or samples to health care workers.

- $\quad$ Technical product information can be given to health workers but this must be factual and scientific.

- $\quad$ No free or low cost supplies to health care system.

- Informational and educational materials should explain the benefits and superiority of breastfeeding, the health hazards associated with bottle feeding, and the costs of using infant formula. 
- $\quad$ Product labels must clearly state the superiority of breastfeeding, the need for the advice of a health care worker and a warning about health hazards.

- $\quad$ No pictures of infants, or other pictures or text idealizing the use of infant formula.

- $\quad$ Unsuitable products, such as sweetened condensed milk, should not be promoted for babies.

- All products should be of a high quality (Codex Alimentarius standards) and should take into account the climactic and storage conditions of the country where they are used.

- Governments are urged to take action to give effect to the principles and aim of Code, as appropriate to their social and legislative framework, including the adoption of national legislation, regulations or other suitable measures.

- Manufacturers and distributors are also called upon to regard themselves as responsible for ensuring that their conduct at every level conforms to the Code.

\section{Effects Of The Code After Twenty-Five Years}

A global assessment of the Code implementation has shown that not only was the setting up of the Code a battle but its implementation has been a battle as well (Mahler in Allian 2005). Twenty-five years after the adoption of the Code, it has not been fully put into effect by all governments through legislation, regulations or other suitable measures as required. By August 2005, sixty-one out of the one hundred and ninety-two (192) countries had not yet passed a law derived from the Code, while many other countries had adopted measures that did not take into account all of its provisions. Globally only, thirty-four (34) out of the one hundred and ninety-two had so far put into effect all of the provisions of the Code and these include Ghana (ICDC - IBFAN 2006). Again, only a few out of the thirty-two countries have put in measures for regular monitoring of their provisions and Ghana is again one of those. The main aim of the Code as mentioned earlier is to protect breastfeeding by regulating marketing practices of infant food manufacturers. The question is how the Code has affected marketing outcomes of infant foods globally. One of the top three world food manufacturers and the world's largest food and infant food manufacturer had in recent times reported that infant formula now makes only about $2 \%$ of the company's total sales though, for about the first 40 years of the company's life since the year 1867, it was the company's principal product. A number of recent market studies have on the contrary shown that there has been a steady increase and currently a boom in market trends of infant foods. "The response of the consumers is very favorable towards the baby food and milk market. The market has seen a rise in conjunction with the increase in the number of working women and their decision to start a family late. The report charts the huge rise in the baby food industry from 1995 till the current times". Another Report by RNCOS further indicated that the drastic changes in the baby food market are due to factors which include; family planning methods, the importance of financial planning before the birth of a child, late pregnancy options exercised by women, the increase in the number of working women, and many more. (Brabeck 2001, RNCOS 2005 and 2006, Corporate Food Pyramid 2006). In all these what has been the effects of the Code?

\section{THE GHANA BREASTFEEDING PROMOTION REGULATION 2000 (LI 1667)}

The enactment of the Breastfeeding Promotion Regulation 2000 (LI 1667) on May 9, 2000 was part of the general effort to support, protect and promote breast feeding in Ghana. The LI 1667 is derived from the International Code of Marketing of Breast milk Substitutes (May 1981), Relevant World Health Assembly resolutions and other relevant Country specific provisions. It is a subsidiary legislation under the Food and Drugs Law, Act 526 of 1992. The aim of the LI 1667 is the same as the International Code of marketing of Breast Milk Substitutes from which it was derived. The main aim is to prevent aggressive marketing of breast milk substitutes, hence protect breastfeeding. It seeks to ensure the safe and adequate nutrition for infants by the protection of breast feeding and to ensure the proper use of substitutes when these are necessary, on the basis of adequate information and through appropriate marketing and distribution. It implements all of the provisions of the Code together with Subsequent relevant WHA resolutions in respect of Infant and Young Child Nutrition in force at the time of drafting. Independent analysis of the Ghana Breastfeeding Promotion Regulation suggests that it is one of the strongest national Laws that regulate the marketing of breast milk substitutes. (ICDC 2000) 
The LI 1667 covers sixteen regulations namely:

1. Prohibition of sale and promotion of designated products

2. Exhibition of manufacture and expiry dates

3. Distribution of free and low cost designated samples

4. Prohibition of display of printed material or designated products in a health care facility

5. Prohibition of donation of equipment and material

6. Provision of Fellowship and Scholarship prohibited

7. Distribution of information and other material

8. Information and educational material

9. Explanatory material

10. Labeling of Designated products

11. Labels on Feeding bottles and teats

12. Labels on Condensed milk

13. Authorized Officer

14. Health personnel to support breastfeeding

15. Offences and Penalties

16. Interpretation

\section{RESULTS AND DISCUSSIONS}

Table 1: Distribution Of Sample Units Monitored

\begin{tabular}{|c|c|c|c|c|}
\hline Regions Monitored & $\begin{array}{c}\text { Number of Districts } \\
\text { Visited }\end{array}$ & $\begin{array}{c}\text { Number of Health } \\
\text { Facilities }\end{array}$ & $\begin{array}{c}\text { No. of Mothers } \\
\text { Interviewed }\end{array}$ & $\begin{array}{c}\text { Number of Sales } \\
\text { Points Monitored }\end{array}$ \\
\hline Greater Accra Region & 4 & 20 & 20 & 25 \\
\hline Central Region & 4 & 25 & 50 & 56 \\
\hline Western Region & 4 & 15 & 50 & 45 \\
\hline Northern Region & 5 & 5 & 12 & 5 \\
\hline Upper East Region & 6 & 17 & 10 & 17 \\
\hline Upper West Region & 5 & 8 & 15 & 5 \\
\hline Total & $\mathbf{2 8}$ & $\mathbf{9 0}$ & $\mathbf{1 5 7}$ & $\mathbf{1 5 3}$ \\
\hline
\end{tabular}

Source: Results of Exercise

\section{Monitoring In Health Facilities}

Table 1 above shows the distribution of the total number of sample units monitored in each Region visited. A total of 90 health facilities including hospitals, clinics, health centers, maternity homes and TBAs were visited in all six regions monitored. Twenty-five (25) were in the Central Region, fifteen (15) in the Western Region, and twenty (20) in the Greater Accra Region, five (5) in the Northern Region, eight (8) in upper west Region and seventeen (17) in the Upper East Region. The number of facilities monitored was limited in some cases by accessibility.

\section{BFHI Status Of Facilities Visited}

Only four (4) out of the twenty-five (25) facilities visited in the central region, three (3) out of the fifteen (15) facilities visited the western region, three (3) out the twenty (20) facilities visited in the Greater Accra Region were baby friendly. A few facilities in the Central Region had applied to be declared baby friendly and the national assessment team was in the region to assess their status at the time of the monitoring exercise. Almost all the government and missionary facilities visited in the Upper East and Northern Regions were baby friendly, no private facility was baby friendly. The Upper West Region on the other hand had no baby friendly designated facility. 
Table 2: Summary Of Observations Made During The Monitoring Exercise

\begin{tabular}{|c|c|}
\hline Regulatory Requirement & Observation(s) \\
\hline $\begin{array}{l}\text { Prohibition of sale and promotion } \\
\text { of Designated products }\end{array}$ & $\begin{array}{l}\text { No direct promotion of designated products in public places, electronic or print media and } \\
\text { health care facilities was observed at the time of the exercise. }\end{array}$ \\
\hline $\begin{array}{l}\text { Distribution of free and low cost } \\
\text { samples }\end{array}$ & $\begin{array}{l}\text { No distribution of free and or low cost samples of designated products observed during the } \\
\text { exercise. However, } 82 \% \text { of facilities regularly visited by company representatives }{ }^{4} \text { had } \\
\text { received Free samples of a particular of non designated brand of Milk-based-Cereal product. }\end{array}$ \\
\hline $\begin{array}{l}\text { prohibition and display of printed } \\
\text { material on designated products } \\
\text { in a health care facility }\end{array}$ & $\begin{array}{l}12 \% \text { of facilities visited had breastfeeding and other health tips posters bearing the name } \\
\text { and logo of Nestle. }\end{array}$ \\
\hline $\begin{array}{l}\text { Prohibition of donation of } \\
\text { equipment and material }\end{array}$ & $\begin{array}{l}\text { No major equipment had been donated by a manufacturer or distributor of designated } \\
\text { products as observed. However, equipment in the form of gifts to health workers like } \\
\text { thermometers, watches, pens writing pads bearing the name and logo of Nestle were } \\
\text { common. }\end{array}$ \\
\hline $\begin{array}{l}\text { prohibition of provision of } \\
\text { fellowship and Scholarship }\end{array}$ & $\begin{array}{l}\text { Only one (1) out of the ninety facilities visited had received a scholarship offer but declined } \\
\text { the offer. }\end{array}$ \\
\hline $\begin{array}{l}\text { distribution of information and } \\
\text { other educational material }\end{array}$ & $\begin{array}{l}92 \% \text { of the facilities regularly visited by company representatives had received } \\
\text { informational brochure of designated products that had promotional effect from only one } \\
\text { company Nestle".(please explain superscript " } 4 \text { " below the table) }\end{array}$ \\
\hline $\begin{array}{l}\text { information and educational } \\
\text { materials }\end{array}$ & $\begin{array}{l}\text { A particular breastfeeding booklet I am breastfeeding my baby" and a few other nutrition } \\
\text { booklets by Nestle seem to be offered along side with the information brochures because } \\
\text { these were found at almost all the facilities where company presence was visible. Only one } \\
\text { facility in the south had an old brochure of Wythe Sma Progress follow-on formula. }\end{array}$ \\
\hline labels of designated products & $\begin{array}{l}\text { only two of the eight brands were fully compliant (Cow and Gate by Nutricia) and (Aptamil } \\
\text { by Milupa), Pre- Nan by Nestle also was almost completely compliant because did not have } \\
\text { the "Second Elaborate picture of the Mother and baby birds in the nest", Frisolac by the } \\
\text { time of compiling this report was fully compliant, no longer has the picture of the blue and } \\
\text { pink bear with the rattle. } \\
\text { Most non-compliant brands were, France Liat } 1 \& 2 \text {, SMA wyethe range (gold, progress, } \\
\text { white, wysoy), Nursie } 1 \& 2 \text {, Nestle Lactogen } 1 \& 2 \text {, and Nestle Nan } 1 \& 2 \\
\text { All other range of infant meals (powder and wet, purees and liquids) labeled as suitable } \\
\text { before six months as required were all highly non compliant. This included brands like: } \\
\text { Purity, Gerber, blendina, Beechnut and Hienz. } \\
\text { Only two infant cereal based meals were fully compliant. These were: Nestle Cerelac range } \\
\text { and Nutrimental infant Cereals labeled from six months and twelve months respectively and } \\
\text { compliant with all other requirements for these products. } \\
\text { The most non compliant product labels were Wyethe SMA range, then France Lait, then } \\
\text { Danaone Nursie then finally Nestle Range in that order. With the new labels Frisloac, } \\
\text { Milupa Enfamil and Cow and Gate were most compliant product labels of designated } \\
\text { products. }\end{array}$ \\
\hline $\begin{array}{l}\text { labels on feeding bottles and } \\
\text { teats }\end{array}$ & $\begin{array}{l}\text { All non compliant. Some with misleading text Like } \\
\text { "Dirt or unmelted milk would not be able to accumulate inside this bottle" (Brand: } \\
\text { Camera) } \\
\text { "clinically Proven to reduce Colic in the Newborn." (Brand: Avent) }\end{array}$ \\
\hline labels on condensed milk & All non compliant \\
\hline
\end{tabular}

Source: Results of exercise

\footnotetext{
${ }^{4}$ Seventy three percent $(73 \%)$ of facilities regularly visited by monitors in the south were regularly visited by company representatives

${ }^{5}$ Seventy-three percent $(73 \%)$ of all facilities visited in the south were regularly visited by only Nestle company representatives to promote their infant food brands.
} 
Company Representatives Visit To The Health Facilities And Their Interaction With Mothers Within Health Care System

Seventy-three percent $(73 \%)$ of the facilities monitored in the south were regularly visited by company representatives to promote their brands but were not allowed to talk or offer samples to mothers though in most instances they requested to do so. Ninety-two percent (92\%) of the facilities regularly visited by company representatives had received various informational brochures of designated products that had promotional effect. In eight-two percent $(82 \%)$ of these facilities, samples of particular brands of complementary foods were offered to health personnel. These samples are however not designated products but their advertisement is highly restricted under the provisions of the Regulations. However, offering free samples of complementary foods to health workers within the health facilities undermined the LI 1667 because it has the potential to create brand awareness for designated products.

\section{Donations To Health Facilities And Gifts To Health Care Workers}

Health Workers in sixty four (64\%) of the facilities regularly visited by company representatives had received various promotional gifts. The gifts ranged from Thermometers, pens, writing pads, video tapes, calendars, breast watches, car stickers and samples of complementary foods. One (1) out of the ninety (90) facilities had received a scholarship offer from Company Representatives but did not accept it.

Only one (1) out of the 90 facilities visited had received donations of designated products over the past one year. These donations were for abandoned babies, babies under intensive care, babies who could not be breast fed for one reason or the other. These included orphans and those with special medical indications. On the whole, the facility procured infant formula through the normal procurement channel for their Neonatal Intensive Care Unit (NICU). The facility had an annual estimated budget for infant formula. Formula was purchased in bulk based on product characteristics such as acceptability by babies, availability and price. The facility did not use the tender system because most babies could not tolerate particular brands. Monitoring further revealed that visits by company representatives also influenced the choice to some extent.

The facility used to rely on donations and assistance from benevolent organizations to stock Breast Milk Substitutes. Experience however, pointed to the fact that often times the donated products were either not suitable for the intended purpose or close to expiry. In two instances before the monitoring, all the donations received were either lumpy or close to expiry and babies could not tolerate these products. The first batch of donation from an NGO had to be discarded and another 480 cans donated by another company that imports and distributes particular brands of infant formulae was also given out to female staff and other interested persons because most of the infants could not tolerate them.

\section{Display Of Promotional Devices Within The Health Facility}

Twelve percent (12\%) of all the facilities visited had violating posters but most of these posters looked old and worn out. Almost all of these were breastfeeding posters bearing the name and logo of a particular company. Almost all of these were breastfeeding posters bearing the name and logo of a particular company.

\section{Health Workers' Knowledge Of Code}

Ninety one percent $(91 \%)$ of health workers had no knowledge of the existence of the Regulation, nonetheless these workers had working knowledge of various aspects of some of the provisions through the Baby Friendly Hospital Initiative (BFHI) trainings. 


\section{Compliance Within Health Care Facilities In The Three Northern Regions}

- There were no observed violations in either government or private health facilities visited in the three northern regions.

- Mothers interviewed were not receiving free supplies, sponsorship, gifts etc. from health workers or companies.

- $\quad$ TBAs played an important role in the provision of delivery services particularly in the Northern part of Ghana.

\section{Interview With Mothers}

Table 3: Results Of Interview With Mothers Of Infants (0-6 Months)

\begin{tabular}{|c|c|c|c|}
\hline Age Range of Babies (Months) & \multicolumn{3}{|c|}{ Number of Babies } \\
\hline & Central Region & Western Region & Greater Accra Region \\
\hline $0-2$ & 20 & 8 & 8 \\
\hline $2-3$ & 1 & 12 & 5 \\
\hline $3-4$ & 5 & 2 & 2 \\
\hline $4-5$ & 15 & 19 & 4 \\
\hline $5-6$ & 9 & 9 & 1 \\
\hline Total & $\mathbf{5 0}$ & $\mathbf{5 0}$ & $\mathbf{2 0}$ \\
\hline
\end{tabular}

\section{Company Representative Interaction With Mothers Outside The Health Care System}

There was no direct contact between companies and nursing mothers. The main link between companies and mothers was the retail outlet and through promotion of complementary foods. This is aimed at brand awareness creation. Another form of company communication is through distribution of breastfeeding and nutrition information materials within the health care system. No samples of designated products were offered to mothers either by company representatives or health workers.

\section{Number Of Babies Consuming Commercial Foods}

Interviews with breastfeeding mothers showed that about ninety-four percent (94\%) of them had substantial knowledge about the advantages of exclusive breastfeeding for six months. Forty-eight percent (48\%) of the mothers however, did not seem to have adequate knowledge about continuing breastfeeding up to the age of two years.

In the three regions in the south, mothers generally preferred to breastfeed. However, it was observed that after three months when most mothers had to return to work whether formally employed or self-employed they were compelled to add other foods. These include infant formula as well as commercial and homemade complementary foods. Fifty-two percent (52\%) of mothers however were determined to breast feed exclusively for the entire recommended six months period. Some had indicated that they preferred to breastfeed exclusively for the recommended period but were normally faced with realities and difficulties that sometimes made this impossible. It was discovered that an unsuspecting number of mothers who claimed to exclusively breastfeed their infants under six month actually offer water as part of the infants' diet. $^{6}$ Most care givers believed that these babies became thirsty and therefore offered water periodically. Others did not believe in the exclusivity of breastmilk but pretended to and therefore tried to save their babies from dehydration by offering water periodically. About eight percent (8\%) of maternity homes actually stocked bottled and sachet water which they sold to mothers after delivery. The Monitoring Team termed a particular brand of bottled water having the picture of a baby on it "baby water" because it had become the status of elitist mothers in most rural and urban poor communities.

\footnotetext{
${ }^{6}$ This could not be quantified accurately since the tool used did not set out to measure this but the revelations came in some instances during interviews with some health workers and audits with children under five. The number of such responses recorded was however, about twelve percent.
} 
Only seventeen (17\%) of mothers interviewed in the Central Region, twenty three $(23 \%)$ in the Western Region and nineteen (19\%) in the Greater Accra region said they fed their babies with commercial infant formula and other replacement foods. In all nineteen and a half percent (19.6\%) of infants were fed infant formula. The figures recorded may not reflect the true picture because in most cases mothers were reluctant to indicate that they fed their babies with commercial infant foods even when they did. However, audits with older children below five years revealed that some mothers who had indicated not to be feeding commercial infant formula and other home made preparations particularly, fermented maize meal porridge to babies below six months actually did so.

Mixed feeding was clearly dominant in the southern part of the country. $12 \%$ of mothers in the Northern regions indicated that they would prefer formula or commercial products if they could afford because of convenience and concerns related to work. $48 \%$ in the south in both rural and urban preferred to feed commercial products from the third month onwards for the same reasons. According to these mothers they would prefer formula because it puts their babies to rest for longer periods than when breastfed and this allows time to attend to other important issues whether at home, including the farm.

\section{Brands Of Formula Consumed}

Seventy-two percent (72\%) of rural mothers indicated that they could not afford infant formula and therefore did not use them. However, $56 \%$ of urban women start using infant formula and other cereal based commercial infant foods from the third or fourth month onwards when they have to go back to work. Though some use moderately priced brands, others prefer the most expensive brands because they relate price to quality. Brands of the biggest and most popular baby food company in Ghana seemed to be the preferred choice of both rural and urban poor mothers because of price and image of the company. Sixty-eight percent (68\%) of mothers interviewed introduce other foods before the end of the sixth month. These products are either commercial or home preparations. Commercial infant formula is not generally found in the rural areas though company representatives' activities seem to cut across all corners of the country. One particular brand of complementary food is highly patronized in both rural and urban areas because it comes in packages of various portions and sizes which makes it affordable and accessible to most mothers. Sixty-two percent (62\%) of the urban poor and rural folks who introduce other foods before six months have at least used this particular brand before. The use and promotion of infant formula was negligible in the three Northern Regions. The few brands available were the moderately priced ones. None of the expensive brands common in the Regional Capitals was spotted in either the northern regions or the rural areas across the country.

\section{Brands Of Cereals Used.}

Popular cereals used in the Western and Central Regions were mostly home made preparations and included mashed kenkey and fermented maize porridge (Koko). It was observed that some of the respondents introduced these foods as early as two months of age 7 , (mostly home preparations). In the Greater Accra Region the commercial brands were the most popular (Seventy-two percent), though a few fed "koko and other home-based maize preparations. Most women in the Greater Accra Region indicated that their babies were not fed commercial foods; however, interview with younger children and shop attendants /owners revealed that the brands were patronized by some mothers with babies less than six months in most urban communities within the three Southern Regions.

It was reported by some health workers in the Northern Regions that some mothers gave a local fermented maize porridge ("koko") and water in some surrounding villages to babies below the recommended six (6) months. The extent of this was not quantified.

\footnotetext{
${ }^{7}$ A mother in the Central Region explained how an aunt had used mashed well strained and very smooth mashed Kenkey to save the lives of two pre-mature babies who were not growing as expected with the help of a nurse at the hospital.
} 


\title{
Promotion At The Points Of Sale And Information To General Public
}

\author{
Monitoring At The Point Of Sale
}

Infant formula is generally sold in the major cities and towns and these could be found either at the supermarkets or food shops, stalls or in kiosks. Eighty-two (82\%) of Pharmacy and licensed chemical shops in all the communities visited except the city of Accra, no longer stocked or sold infant formula. This became evident when eighty-two percent $(82 \%)$ of all the pharmacies and licensed chemical shops visited except in the Greater Accra Region indicated that they had stopped stocking infant formula and because of low patronage as a result of the emerging breastfeeding practices. The extent of this could not be quantified because this fell out of the scope of this study. A few still stocked complementary food but these are not under the product scope in the provisions of the Regulations under consideration. In most of the rural areas visited, complementary foods were common. This was because aside being relatively cheaper they were also available in very small sachet (one meal portion sizes) which made it affordable to most rural or urban poor dwellers.

\section{Promotion At The Point Of Sale}

No direct promotion of designated products was observed throughout the monitoring except for a particular brand of bottled water labeled as suitable for babies which had posters displayed at a few shops visited. However, indirect promotion of particular brands of designated products existed through the display of posters and other promotional displays of complementary foods with the same company name and logo.

\section{Advertisement To General Public In News Media}

No advertisement of designated products to the general public either in the print or electronic media, was observed before or during the monitoring period. However, numerous billboards of particular brands of complementary foods were present in almost all the regional capitals visited. These complementary products were not however, advertised on the TV or Electronic Media just before or during the monitoring period.

\section{Labeling Of Designated Products}

Results on labeling requirements are summarized in the Table 2. Six out of the eight brands of infant formula available did not fully comply with the labeling requirements. Some feeding bottles also had labeling information that was either misleading or idealizing. Such misleading labeling text included: "Dirt or unmelted milk would not be able to accumulate inside this bottle" and "clinically proven to reduce Colic in the Newborn."

\section{Labeling Of Condensed Milk}

Labels of a Condensed Milk did not bear any clear, conspicuous warning that they should not be used for feeding infants as required by the regulations. The use of condensed milk is quite widespread in the Western and Central regions where some mothers added it to either porridge or mashed "kenkey" for their infants. These mothers preferred condensed milk because one need not buy sugar when using condensed milk. These mothers were not aware that these milks are not suitable for infants.

\section{DISCUSSION}

\section{Relevance Of The LI 1667}

The Breastfeeding Promotions Regulations 2000, (LI 1667) has effectively stopped advertisements of designated products and reduced other commercial promotional activities of infant foods. Since the breastfeeding Regulations came into force, companies have stopped most of the blatant public promotion of designated products that occurred prior to the Regulation. However, this is not as much as they are required to do under the law. Companies keep devising new ways to circumvent the Regulations by taking advantage of certain provisions. It can be inferred 
from observations made during the monitoring exercise that there is a decline in sales of infant formula in Ghana. This could be attributed to the effects of the Regulations on the promotional activities of infant food companies. The argument here could form the basis for further research. The CSPI Report supports this view when it stated that "Advertising Campaigns promote the myth that commercial products are especially good at meeting the nutritional and developmental needs of infants" (Stallone and Jacobson 2003). In addition, the observed trends in the sales of infant formula in Ghana could also be attributed to the strong exclusive breast feeding advocacy and emerging exclusive breastfeeding practices. This study however, confirms that in line with the global market report on infant food marketing trends; follow-up formula and commercial cereal based products are the emerging favorable market trends in the infant food industry in Ghana. This is because the state of the Ghanaian economy dictates an increase in the number of working women. The observed market trend in Ghana can to some extent also be attributed to the nature of the breastfeeding advocacy which had laid more emphasis on exclusive breastfeeding and indirectly down played the need for continuous breastfeeding after six months.

\section{Challenges Facing Ghana In Regulating The Marketing Of Breast Milk Substitutes}

Ghana's experiences with the implementation of the Code through the Breastfeeding Regulation cannot be said to be without challenges. The major challenges include, Labeling, Distribution of informational and educational materials by manufacturers, importers and distributors to health workers, which could in some cases extended to mothers. The health care system has become the main promotional point because the Regulations allow informational materials to be distributed to health workers. This is the biggest challenge because the line between information and promotion is very thin and very often, promotion gets passed in the form of information and other tangible forms from health workers to mothers which in essence contravene the aims of the regulations.

Apart from informational materials, gifts to health workers are another major challenge limiting full compliance with the Law. Gifts have normally been employed as effective tools for inducement. Gifts to health workers are therefore a subtle means of promotion for baby food marketing companies in Ghana since, all such gifts found in the health care system bore both the logo and brand name of the particular company.

\section{Effects Of The Law And Feeding Practices}

The existence of the regulation or its enforcement has not directly influenced feeding practices within the health care system. Rather, the strong breastfeeding advocacy and the Baby Friendly Hospital Initiative (BFHI) have. Under the Baby Friendly Hospital initiative, facilities are required to implement the ten steps to successful breastfeeding which incorporates some aspects of the Regulation. This has to a very large extent changed healthcare practices that undermine breastfeeding, hence positively influencing mothers feeding practices. Eigthy nine percent (89\%) of all health workers interviewed were not aware of the existence of the Breastfeeding Regulations but have working knowledge of some aspects of the Regulations because these are requirements within the BFHI concept. As a result, the first food for most babies at the facility level is breastmilk rather than infant formula. This is in line with the fact that more than seventy percent $70 \%$ of mothers do initiate breastfeeding appropriately and do continue to breast feed predominantly at least up to three months (GDHS 2003). The observed decline and other trends in sales of infant formula at pharmacies and licensed chemical shops supports the reported increase in exclusive breastfeeding rates of the first three months and the decrease in bottle feeding over the last five years (GDHS). However, in some cases with water, particularly bottled water. Some brands of water still bear on their labels either the inscriptions "suitable for babies" (Yes mineral water) or bear the picture of babies which position such bottled and sachet water as "baby water" (Voltic mineral water), which contravenes the law. In addition, after three to four months most of the mothers do mix feed mainly because they have to go back to work whether self employed or formally employed. The GDHS 2003 confirms that supplementary feeding of infants begins early with a rate as high as thirty-eight percent among infants under two months old. In Ghana, most children are actually predominantly breastfed. Pre-dominant breastfeeding is when children are either exclusively breastfed or receive breastmilk and plain water, water based liquids, and or juices. However, analysis of available data and observations made during the monitoring exercise suggests that currently, infant formula may not contribute as much to the supplementary feeding of infants in Ghana within the first two to three months of life. Bottle-feeding is reported to have declined markedly over the past five years. This is because according to the GDHS 2003, only $12 \%$ of infants under six months are given a feeding bottle 
with a nipple with bottle feeding reaching its peak of $15 \%$ at age $4-5$ months as compared to $26 \%$ bottle feeding rate in 1998. The current data of $38 \%$ of infants under six months receiving supplementary foods before two months of age could be attributed in part or a large to other water-based home-made foods or other commercial food not only infant formula. Exclusive breast feeding rate drops sharply from $65 \%$ by $2-3$ months to $39 \%$ by at age $4-5$ months. In addition, six percent (6\%) of infants at age 2-3 months and 32\% at age $4-5$ months are receiving complementary foods in addition to breastmilk (GDHS 2003). These infants are likely to be receiving supplementary foods or liquids ranging from water, infant formula and particularly fermented maize meal porridge with mashed kenkey commonly used by mothers offering supplementary foods in the Western and Central regions. This opens up another area for further research.

The breast versus bottle supposition has to some extent obscured the real picture of infant feeding practices in Ghana. By inference, the vast majority of mothers in Ghana breastfeed and at the same time give their babies some of the above-mentioned traditional foods, or just plain water. It has also been noted that many of the countries with the lowest exclusive breastfeeding rates are also those with the lowest formula use. (Pindelwa Mda, 2001). According to data in the GDHS exclusive breastfeeding rate is shorter in the rural areas with duration of one month as compared to four months in urban areas. Exclusive breastfeeding is also reported to increase with increases in mother's level of education and wealth quintal (GDHS 2003). The study confirms the fact that the vast majority of mothers in rural communities do not have the means to buy infant formula. It can be deduced therefore that if the duration of exclusive breastfeeding is relatively much lower in rural areas then there is need to look more into the feeding practices of mothers in rural poor and urban communities. In Ghana, the problem may not only lie in the fact that poor families often over-dilute costly formula with unclean water and mix them in unclean bottles, adding to the risks of bottle feeds but in addition, most poor families either cannot afford or do not have access at all to infant formulae and therefore substitute breastmilk with other inferior home made preparations with poor nutritional values. Early supplementation could be linked to entrenched cultural practices as well as the failure to disseminate LI 1667 among health workers and parents or caregivers.

Apart from employment concerns and issues of convenience, the aggressive promotion of commercial complementary foods and the sale of homemade complementary foods by health workers within the health care system may also contribute to the introduction of these products before the six months recommended age.

\section{The Law And Complementary Foods}

Though commercial complementary foods are not under the product scope of the LI 1667, provisions on information under section eight cover all infant foods which include complementary foods marketed from six months onwards. At the time of the survey, there was no electronic advertisement of any infant foods including complementary food. All the bill boards encountered in the monitoring were for various brands of complementary foods with one brand representing $84 \%$. Most locally available complementary foods do not fully comply with the labeling requirement of the regulation and are not properly, safely and attractively packaged.

\section{CONCLUSION}

Ghana has come a long way in Code implementation as compared to other countries with and without a national Code. Ghana's experience confirms that a strong law can effectively regulate advertisement and protect breast feeding. Compliance with the Law was generally observed to be satisfactory. Public advertisements of products under the scope of the Law were virtually non-existent. The study suggests that a strong national law can also support breastfeeding efforts. This is because exclusive breastfeeding rates are reported to have increased over the last five years. This study also observed a trend that suggested a decline in sale of infant formula due to reported low patronage by most pharmacies, licensed chemical shops and other sales points visited. Practices at the health facility level that undermine breastfeeding were also observed to be minimal. Though company activities within the health facilities are quite aggressive the Law has restricted these activities to a large extent. These positive effects could have contributed in the gains made in early initiation of breastfeeding. It can therefore be deduced that having a national measure to regulate commercial promotion of infant foods is a pre-requisite for the protection of breastfeeding but such a law on its own does not promote breastfeeding or appropriate infant feeding practices though it can in addition to the 
protection support breastfeeding. Whereas the BFHI concept has enhanced breast feeding practices at facility level, the law has effectively restricted promotional activities at the facility level.

Contrary to current global market trends of infant foods which have been reported to be very favorable with a steady and huge rise since 1995 and currently experiencing a boom (RNCOS Report 2005), Ghana's trend may not be described as being the same. The monitoring exercise suggests that the sales of infant formula could be declining because of the strong breastfeeding advocacy and the existence of the Breastfeeding Promotion Regulation. The regulations have effectively restricted promotional activities of infant food companies whilst the strong breastfeeding advocacy have resulted subsequently in the emerging exclusive breastfeeding practices during the first three months of most babies' lives. The LI1667 may not have influenced feeding options directly but indirectly through its effects on promotional activities of infant food companies. This can be linked to the fact that $89 \%$ of health-workers interviewed are not of aware of LI1667 though they have some working knowledge of it through the BFHI trainings.

It can also be suggested that the "Breast versus the Bottle supposition" has masked some of the key issues of concern regarding appropriate infant feeding practices. The monitoring revealed that most of the rural areas where no formula could be found or where the use of formula seemed to be limited were rather the areas where according to the GDHS 2003 exclusive breastfeeding rates are either lowest or decline faster. Observations made during the exercise point to the fact that infant formula is not the only product that competes with breast milk during infancy but also home made preparations which in most cases are inferior. The observations made, suggest a rather weaker competition from infant formula for the first six months of life than home made preparations. Many infants breastfed are by tradition also given water mixed with local foods even from first 1-2 months of life. This is the real reason why emphasis on exclusive breastfeeding for the first 6 months of life should be continued together with continued breasfeeding to two years or beyond.

Finally, the study suggests that having a national law or legal provision in respect of infant nutrition and commercial practices is a condition that can ensure balance, transparency and accountability between infant health and trade dynamics, if properly implemented. Having a law is indeed imperative but this must be supported by enforcement, dissemination, monitoring, training and strong breastfeeding advocacy.

\section{Way Forward}

The issue of mixed feeding before six (6) months should be investigated and discouraged through sensitization programmes at the community level not only at the facility level. The breastfeeding advocacy should adequately reflect the need for continuous breastfeeding after the six months period as well as the timely and appropriate introduction of complementary foods. Regulatory bodies must begin to extend enforcement to cover feeding bottles teats and condensed milks. To be effective the Regulations must be adequately disseminated. Besides, there is the need for health workers particularly nurses who manage health facilities in the rural areas to understand the circumstances under which infant formula could be used since under some conditions it becomes very relevant to offer artificial formula to safe a life. Expression of breast milk should also be made part of antenatal grooming rather than the case to case basis.

\section{ACKNOWLEDGEMENT}

This work was sponsored by UNICEF Ghana, supported by WHO Ghana, the Ghana Health Service, the Ministry of Health, the Ministry of Local Government and Rural Development and the Food and Drugs Board.

We thank the Health Workers, mothers and children who participated in this study for their cooperation and patience. Finally, we thank the ICDC for their immense support and Joo Kean, Legal Advisor of ICDC for technically editing this paper and her technical input that has sharpened this paper. 


\section{REFERENCES}

1. Allian A. 2005, Fighting an Old Battle in a new World: How IBFAN Monitors the Baby Food Market, In the Development Dialogue, A Journal of International Development Cooperation, Dag Hammarskjold Foundation Centre, Uppsala, Sweden, pp.7-21,41, 77-94

2. $\quad$ Arifeen S, et al Reducing child mortality: can public health deliver? - The Lancet, 2003

3. Bellamy C 2000, Unicef and Baby Food Manufacturers. BMJ 2000; 321: 960

4. Black S., et al Where and why are 10 million children dying every year?. The Lancet, Volume 361, Issue 9376, Pages 2226-2234

5. Brabeck P and Pindelwa Mda. 2001 Infant Feeding in the Developing World Nestle, South Africa, Johannesberg

6. Costello A, and Sachdev HS. Protecting breast feeding from breast milk substitutes. BMJ 1998; 316:1103-4.

7. Corporate Food Pyramid, 2006, Brands and Logos and their effects - A focus on the Food Industry, http://www.holology.com/food.html\#20,

8. Economic Research Service/USDA, WIC and the Retail Price of Infant Formula / FANRR-39

9. Edmond K. et al., Delayed breastfeeding Initiation increases Risks of Noenatal Mortality. PEDIATRICS Vol. 117 No. 3 March 2006, pp. e380-e386 (doi:10.1542/peds.2005-1496)

10. IBFAN 2000, Ghana law: Breast feeding promotion regulation 2000, Full text with ICDC Analysis ICDC, PINAN Malaysia $1-16$

11. Jones G, Steketee RW, Black RE, Bhutta ZA, Morris SS and the Bellagio Child Survival Group. How many deaths can we prevent this year? Lancet 2003; 362:65- 71.

12. Kean YJ. Nestlé's violation of international marketing code. Audit's report fudges the issue. $B M J$ 2000;321:959-60.

13. KOTLER, P. (1991). Marketing management: Analysis, planning, implementation and control. Ed. 7 Englewood Cliffs N.J. 596 DS)

14. Kramer $\mathrm{M}$ et al Promotion of Breastfeeding Intervention Trial (PROBIT): A randomized trial in the republic of Belarus. Journal of the American Medical association, 2001,285 (4):413-420

15. Mashewari S., 2006, Baby Food Market - An Outlook, Summary Report RNCOS, http://www.researchconnect.com/downloadreport/report 7705.asp

16. Mashewari S., 2006, Baby Food Market-Organic and Inorganic: A market Study, RNCOS,

17. Nestle International 2003, (WHO) Code Action Report Number 6

18. Palmer G, The Politics of Breastfeeding, London: Pandora Press, 1993 (2d ed.);

19. RNCOS Baby Food Industry (2006) http://www.mindbranch.com/products/R459-778 toc.html

20. Scott T and Drew A., 2005, The Methodist Church Press Release - Methodist ethical investment committee announces Nestlé decision, Methodist Church House, 25 Marylebone Road, London NW1 5JR

21. Sokol E, 2005, The Code Handbook: A Guide to Implementing the International Code of Marketing of Breastmilk Substitutes, ICDC-IBFAN, Penang: -Malaysia, pp.12-22

22. Stallone DD and Jacobson M.F, 2003 CSPI Reports Cheating Babies: Nutritional Quality and Cost of Commercial Baby Food

23. Taylor A., Violations of the code of marketing of breast milk substitutes: prevalence in four countries", $B M J$ 1998; 316: 1117-1122

24. WHO 1998, Supporting Breastfeeding: The special role of maternity services, 1989; WHO/CHD, Evidence for the 10 Steps to Successful Breastfeeding, Geneva: WHO/CHD/98.9, 1998

25. WHO/UNICEF, 1990 The Innocenti Declaration - Breastfeeding in the 1990's: A Global Initiative. 49. WHO/UNICEF, Joint Statement: Protecting, Promoting and supporting breastfeeding

26. Van Trijp, J.C.M, Steenkamp J.E.B.M.1998, Consumer Oriented New Product Development: Innovation of Food Production Systems. Jongen W.M.F., Meulenberg, M.T.G. (eds.). Wageningen pers, Wageningen, The Netherlands. 37-66.

27. Victor M Aguayo, Jay S Ross, Souleyman Kanon, Andre N Ouedraogo Monitoring compliance with the International Code of Marketing of Breastmilk Substitutes in west Africa: multisite cross sectional survey in Togo and Burkina Faso BMJ VOLUME 32618 JANUARY 2003 bmj.com

28. Walker A.RP and Adam F., 2000, Breast-feeding in sub-Saharan Africa: outlook for 2000, Journal of Public Health Nutrition 3(3), 285-292, Johannesburg, South Africa 
29. Waterston and Tumwine, BMJ 2003 326: 113-114

30. World Health Organization, International code of marketing of breastmilk substitutes. Geneva: World Health Organization, 1981.

31. World Health Organization, International code of marketing of breastmilk substitutes. Geneva:World Health Organization, 1981.

32. WHA Resolution 54.2 and Resolution 55.25 is found on www.who.int/gb/ ALINORM 03/26A: Report of the 24th Session of the Committee on Nutrition and Foods for Special Dietary Uses held in Berlin 4-8

November 2002 is found on: http://ftp.fao.org/codex/alinorm03/al0326ae.pdf

33. WIC and the Retail Price of Infant Formula / FANRR-39 Economic Research Service/USDA ERS analysis of InfoScan supermarket data.

34. World Bank Report, 2006, Reposition Malnutrition as Central to Development: A strategy for Large scale action, Bardouy J. and Sarbid J. Forward, pp.xi.

35. World Health Organization, Nutrition for Health and Development, Geneva, Switzerland, May 2000. Document WAH45/1992//REC/1, Annex 9, paragraphs 45 - 51.

36. A progress report on preparations for the ICN, 1986 Programme News, under FAO/WHO. The Politics of Baby Foods: Successful Challenges to an International Marketing Strategy, London: Frances Pinter,

37. WHO web page on Child and Adolescent Health and Development: Nutrition, Infant and Young Child.

38. Joint FAO/WHO Workshop on Enterobacter sakazakii and other Microorganisms in Powdered Infant Formula, Geneva, 2-5 February 2004: www.who.int/foodsafety/micro/meetings/feb2004/en Enterobacter sakazakii and other microorganisms in powdered infant formula, Geneva, FAO/WHO, 2004

39. www.who.int/foodsafety/publications/micro/en/es.pdf International Food Safety Authorities Network, INFOSAN, information Note No. 1/2005, Enterobacter sakazakii

\section{NOTES}




\section{NOTES}

